\title{
Modelling spiral grain angle variation in New Zealand-grown radiata pine
}

\author{
John R. Moore*, Dave J. Cown and Russell B. McKinley
}

\begin{abstract}
Background: Spiral grain angle (SGA) is a wood property that has a strong influence on end-product quality, particularly for solid timber, and most commercial log and timber grading rules restrict the amount of visible surface sloping grain. The aim of this study was to develop parametric models that can be used to predict the intra- and inter-stem variation in SGA in radiata pine (Pinus radiata D.Don) trees growing in New Zealand.

Methods: Empirical models were developed using a dataset that contained records from over 1,100 trees that had SGA measured in both the radial direction and at different heights up the stem. Linear and nonlinear model forms were evaluated for their ability to predict the radial variation in SGA.

Results: Most values of spiral grain angle were between $-5^{\circ}$ and $+10^{\circ}$, with a few extreme values (up to $20^{\circ}$ ) observed. A simple linear model based on cambial age was able to account for the radial variation in SGA outside of the innermost growth rings, but only explained $26 \%$ of the overall variation in SGA. Including a relative height term in this linear model increased the proportion of variation in SGA explained to $30 \%$. A variance components analysis showed that $78 \%$ of the variation in SGA occurred within individual stems, with only $7 \%$ of the variation due to differences between sites.

Conclusions: Our results confirmed that SGA decreased from the inner growth rings to the bark and increased with height up the stem, with low values of SGA only found in the lower peripheral part of the stem. Given that the data came from a wide range of sites, the relatively small amount of inter-site variation was unexpected. The models developed here can be incorporated into a growth and yield simulation system to enable forest managers to compare the potential impacts of different factors on the size of the corewood zone in a tree containing wood with high SGA.
\end{abstract}

Keywords: Spiral grain; Grain angle; Radiata pine; Wood properties; Radial variation

\section{Background}

Spiral grain is a regular feature of many tree species, and remains one of the most important factors influencing wood utilisation (Denzler et al. 2015). However, the factors controlling its formation are poorly understood (Harris 1989; Kubler 1991; Skatter and Kučera 1997). Spiral grain angle (SGA) is defined as the orientation of wood fibres or tracheids with respect to the longitudinal axis of the tree stem (Kozlowski et al. 1967). Changes in the grain angle within stems are a well-known feature of old trees and of the corewood of conifers, and are normally attributed to pseudotransverse and anticlinal cell division in the vascular cambium (Bannan 1966; Larson

\footnotetext{
* Correspondence: john.moore@scionresearch.com
}

Scion, Private Bag 3020, Rotorua, New Zealand
1994; Schulgasser and Witztum 2007). Spiral grain is an important defect is sawn timber and is a primary source of twist distortion during drying (Ormarsson and Cown 2005).

Given both the lack of understanding of the nature of spiral grain in trees and its impact on end-product performance, there is a need to understand how it varies within and among trees. In radiata pine (Pinus radiata D.Don), as in other species (Brazier 1965; Northcott 1957; Pape 1999; Sall 2002), there is a degree of systematic variation in spiral grain angle within stems (Cown et al. 1991a; Cown et al. 1991b). Most stems have near zero values of SGA adjacent to the pith followed by increasing positive angles (upwards to the left as viewed from the bark) over the next few rings to a maximum at

\section{实 Springer}


around rings six to ten, before declining again to about the $15^{\text {th }}$ ring and often changing to negative angles as the trees mature. The characteristic within-tree pattern varies between species and individuals (Harris 1989; Pape 1999; Sall 2002). Longitudinal trends in radiata pine SGA are less well characterised. Some authors report minimal variation with tree height (Tsehaye and Walker 1995). However, most studies in radiata pine, including Cown et al. (1991b) and Cown et al. (2010) noted that higher values of SGA were generally observed in the upper portion of the stem. Similar results were reported in Sitka spruce (Picea sitchensis (Bong.) Carr.) by Pape (1999). Although circumferential variation in grain angle has been noted on log exteriors and inside radiata pine stems (Cown et al. 2010; Watt et al. 2013), the degree of variability in within-stem and between-stem patterns and its potential importance in radiata pine is largely unknown. Despite all of the SGA measurements that have been made, good models to predict the withinand between-tree variation in radiata pine do not exist.

Empirical models describing the radial trends in SGA have been developed for several species, including Sitka spruce (Fonweban et al. 2013) and Norway spruce (Picea abies (L.) Karst.) (Gjerdrum and Bernabei 2009; Gjerdrum et al. 2002). Despite the large amount of data that have been collected on SGA in radiata pine in numerous published and unpublished studies, there has not been a systematic analysis of these data in order to quantify the within and between-tree variation in SGA and to develop empirical models of the radial and longitudinal variation in SGA. The only empirical models that have been developed were fitted to data from 90 trees sampled in Kaingaroa Forest (Tian et al. 1995). Therefore, the objectives of this study were to: (1) collate historic data on spiral grain variation in radiata pine in New Zealand; (2) develop models that can explain the intra-stem variation (radial and longitudinal) in SGA for different sized trees; and (3) investigate the extent to which these intra-stem patterns are affected by site and silvicultural factors and the need for including future adjustments in the models.

\section{Methods}

\section{Data sources}

A database was assembled containing spiral grain angle measurements collected during numerous published (Cown and McConchie 1981; Cown et al. 1991b; Lausberg et al. 1995; Young et al. 1991) and unpublished studies. The latter have often been written up as internal or client reports, but as they are not officially published cannot be cited in the references. However, such reports may contain valuable information so details of relevant ones are provided (see Additional file 1 for more details). The data included in this study were collected from 57 stands that ranged in age from 11 to 35 years and were located across the full range of latitudes from the extreme north to the extreme south of New Zealand (Fig. 1, Table 1). Data were obtained from 1535 individual radiata pine trees. In most cases, at least ten trees were sampled per stand and measurements were made at four heights up the stem of each tree (normally the base, $1.4 \mathrm{~m}, 5 \mathrm{~m}$ and then at $5 \mathrm{~m}$ intervals to a top diameter of $100 \mathrm{~mm}$ ). Spiral grain angle data were obtained from the original studies. In all cases, the SGA measurements had been made using the axis of the disc as the reference, according to the method described by Brazier (1965). Each selected growth ring had been assessed by exposing the latewood with a chisel and scribing along the grain with a "grain detector" (Harris 1989). Grain angle had been measured with respect to the upper surface of the disc. Values for equivalent rings on either side of the pith had then been averaged to remove the effect of disc skew. Spiral grain angle was never measured in the ring closest to the pith as it was always assumed to be zero degrees. Values were measured on every second ring starting from ring two in some studies but on every fifth ring starting from ring five in others.

Total tree height was not measured in almost all of the studies. Because of the different tree ages in the

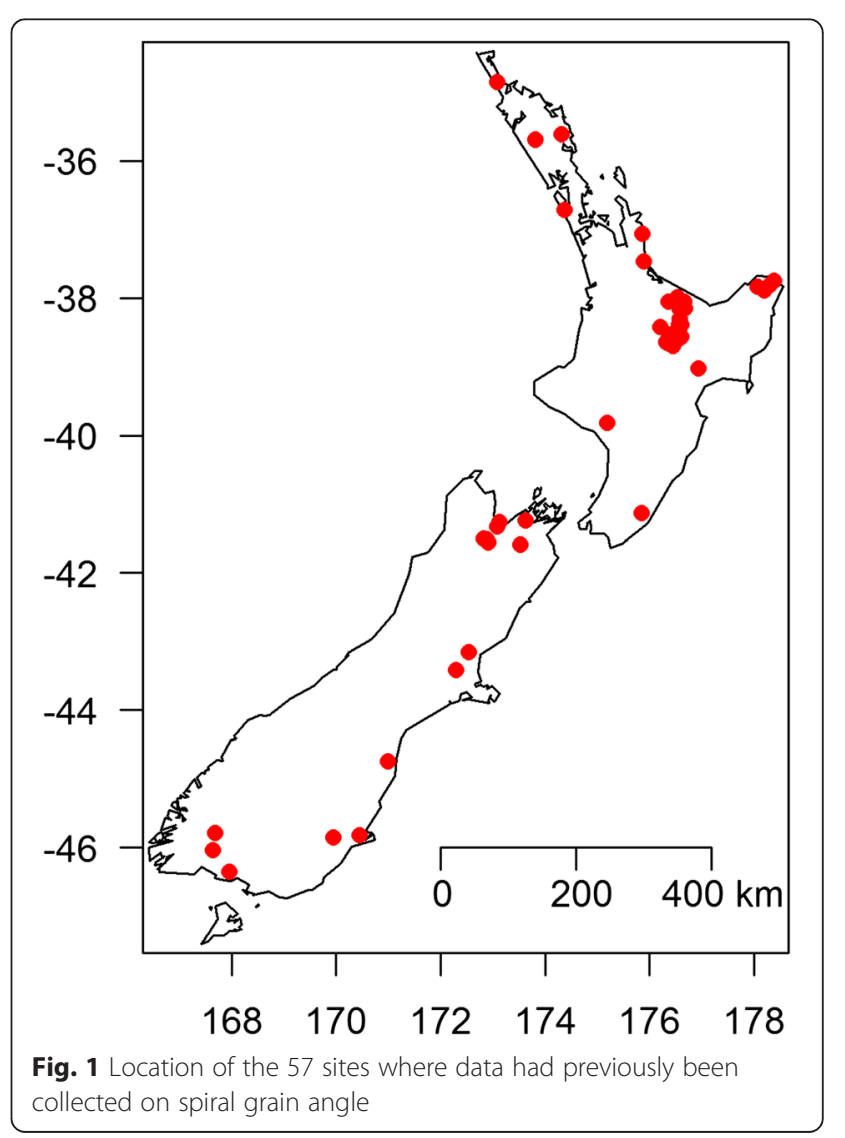


Table 1 Summary of the data used to develop models of spiral grain angle

\begin{tabular}{llllll}
\hline Region & Number of stands & Age range $(\mathrm{yrs})$ & No. of trees & Diameter at breast height $(\mathrm{cm})$ & Estimated total height $(\mathrm{m})$ \\
\hline North Island & & & & & $24.0-68.0$ \\
Northland & 7 & $11-33$ & 261 & $22.9-82.0$ & $13.5-44.7$ \\
Central North Island & 28 & $11-35$ & 918 & $22.5-75.5$ & $11.2-51.0$ \\
East Coast/Hawke's Bay & 5 & $17-26$ & 161 & $31.5-66.2$ & $33.8-47.5$ \\
Southern North Island & 2 & 25 & 16 & & $31.2-45.0$ \\
South Island & & & & $22.7-70.5$ & $30.9-51.1$ \\
Nelson & 7 & $25-33$ & 114 & $28.8-60.5$ & $24.7-36.0$ \\
Canterbury & 3 & 25 & 30 & $35.3-66.8$ & $23.3-39.9$ \\
Otago/Southland & 5 & $25-26$ & 35 & $22.5-82.0$ & $11.2-51.1$ \\
Overall & 57 & $11-35$ & 1535 & & \\
\hline
\end{tabular}

dataset and the need to be able to predict the intrastem patterns in SGA for a wide range of tree sizes, it is useful to know the relative height that each sample was taken from as well as the absolute height. To overcome this problem, total height was predicted for each tree using the same approach that was taken for the dataset used to develop a model of radiata pine microfibril angle (Moore et al. 2014). This involved using a compatible volume and taper function (Katz et al. 1984) along with data on the diameter and heights of each disc sampled from the tree. For each tree, the estimated value of total height was increased incrementally and the difference between the actual and predicted diameters of the discs determined. The predicted height of each tree was selected, such that the difference between actual and predicted disc diameters was minimised. Total height could not be predicted for those trees where SGA had only been measured on a disc taken from a single height. This reduced the number of trees in the final dataset to 1133 .

\section{Data analysis}

Because the data had a hierarchical structure (i.e. growth rings within discs, within trees, within stands), a mixed modelling approach was adopted similar to that used in other studies that have developed ring level wood properties models (e.g. Auty et al. 2013; Jordan et al. 2005; Moore et al. 2014). A variance components analysis was undertaken to determine how much of the variation in spiral grain angle was attributable to each stratum (i.e. site, tree, disc or ring) in the dataset. A number of different model forms were then evaluated for their ability to explain the radial trends in SGA. Once the most suitable model form was identified, the second step was to determine whether the model parameters varied as a function of height within the tree. Model selection was based on visual appraisal of plots of the normalised residuals versus fitted and explanatory variables
(Pinheiro and Bates 2000) and Akaike's information criterion (AIC; Akaike 1974). The AIC is used when comparing models with different numbers of parameters fitted to the same dataset and the model with the lower AIC is generally preferred. Parameter estimates were obtained using the maximum likelihood method, and only those parameters that were significant $(p<0.05)$ were retained in the final models. In order to estimate how much of the variation in SGA was explained by the models, two sets of fit indices $\left(R^{2}\right)$ were calculated using the equations given in Parresol (1999). In the first set, the predicted values were estimated from only the fixed effects terms of each model, and in the second, they were calculated from both the fixed and random effects. All statistical analyses were carried out using functions contained in the nlme library (Pinheiro et al. 2012) of the $R$ statistical programming environment ( $\mathrm{R}$ Development Core Team 2013).

Three different model forms were used to explain the radial variation in SGA. The first was a simple linear function that is based on the approach taken by Gjerdrum et al. (2002) to model SGA in Norway spruce. The difference in the current study is that radial distance from pith was replaced with ring number from the pith, so that the model has the following form:

$$
y_{i j k l}=\gamma_{0}+\gamma_{1} C A_{i j k l}+c_{0, i}+c_{0, i j}+c_{0, i j k}+\varepsilon_{i j k l}
$$

where, $y_{i j k l}$ and $C A_{i j k l}$ are the mean SGA (degree) and cambial age (years), respectively, of the $l^{\text {th }}$ annual growth ring in the $k^{\text {th }}$ disc of the $j^{\text {th }}$ tree from the $i^{\text {th }}$ site, $\gamma_{0}$ and $\gamma_{1}$ are the fixed effects parameters and $c_{0, i}, c_{0, i j}$ and $c_{0, i j k}$ represent the random effect of $\gamma_{0}$ at the $i^{\text {th }}$ site, $j^{\text {th }}$ tree in the $i^{\text {th }}$ site and $k^{\text {th }}$ disc in the $j^{\text {th }}$ tree in the $i^{\text {th }}$ site, respectively; $\varepsilon_{i j k l}$ is the random error due to the $l^{\text {th }}$ annual ring of the $k^{\text {th }}$ disc from the $j^{\text {th }}$ tree at the $i^{\text {th }}$ site. The 
second model form was based on the approach taken by Tian et al. (1995), who modelled SGA as a function of the natural logarithm of cambial age:

$$
y_{i j k l}=\delta_{0}+\delta_{1} \log C A_{i j k l}+d_{0, i}+d_{0, i j}+d_{0, i j k}+\varepsilon_{i j k l}
$$

where, $y_{i j k l}$ and $C A_{\mathrm{ijkl}}$ are the mean SGA (degree) and cambial age (years), respectively, as defined in Eq. $1, \delta_{0}$ and $\delta_{1}$ are the fixed effects parameters and $d_{0, i}, d_{0, i j}$ and $d_{0, i j k}$ represent the random effects of $\delta_{0}$ at the site, tree and disc levels, respectively.

The third model form was the nonlinear function used by Fonweban et al. (2013) to model the radial variation in Sitka spruce spiral grain angle. This model has the following form:

$$
\begin{aligned}
y_{i j k l}=\left(\left(\omega_{0}\right.\right. & \left.\left.+o_{0, i}+o_{0, i j}+o_{0, i j k}\right)+\omega_{1} C A_{i j k l}\right) e^{\left(-\omega_{2} C A_{i j k l}\right)} \\
& +\varepsilon_{i j k l}
\end{aligned}
$$

where, $y_{i j k l}$ and $\mathrm{CA}_{\mathrm{ijkl}}$ are the mean SGA (degree) and cambial age (years), respectively, as defined in Eq. 1, $\omega_{0}, \omega_{1}$ and $\omega_{2}$ are the fixed effects parameters and $o_{0, i}, o_{0, i j}$ and $o_{0, i j k}$ represent the random effects of the $i^{\text {th }}$ site, the $j^{\text {th }}$ tree in the $i^{\text {th }}$ site and the $k^{\text {th }}$ disc in the $j^{\text {th }}$ tree in the $i^{\text {th }}$ site, respectively.

The fixed effects parameters in the three models given by Eqs. (1, 2 and 3 ) were also modified to include the influence of height. Linear, log-linear and quadratic height terms were added to the model following the approach described by Jordan et al. (2005). Because ring width data were not available for most of the sites, this variable could not be included in the models. In the two linear models (Eqs. (1 and 2)), terms representing both the relative height and the interaction between relative height and cambial age were added to the model, while in the nonlinear model given by Eq. (3) relative height terms $\left(\mathrm{HT}_{\text {rel }}\right)$ were added to each of the parameters, i.e.

$$
\begin{aligned}
y_{i j k l}=\gamma_{0} & +\gamma_{1} C A_{i j k l}+\gamma_{2} H T_{r e l, i j k}+\gamma_{3} H T_{r e l, i j k} C A_{i j k l} \\
& +c_{0, i}+c_{0, i j}+c_{0, i j k}+\varepsilon_{i j k l} \\
y_{i j k l}=\gamma_{0} & +\gamma_{1} C A_{i j k l}+\gamma_{2} \log H T_{r e l, i j k}+\gamma_{3} \log H T_{r e l, i j k} C A_{i j k l} \\
& +c_{0, i}+c_{0, i j}+c_{0, i j k}+\varepsilon_{i j k l} \\
y_{i j k l}=\delta_{0} & +\delta_{1} \log C A_{i j k l}+\delta_{2} H T_{r e l, i j k}+\delta_{3} H T_{r e l, i j k} \log C A_{i j k l} \\
& +d_{0, i}+d_{0, i j}+d_{0, i j k}+\varepsilon_{i j k l}
\end{aligned}
$$

$$
\begin{aligned}
y_{i j k l}=\delta_{0} & +\delta_{1} \log C A_{i j k l}+\delta_{2} \log H T_{r e l, i j k} \\
& +\delta_{3} \log H T_{r e l, i j k} \log C A_{i j k l}+d_{0, i}+d_{0, i j} \\
& +d_{0, i j k}+\varepsilon_{i j k l}
\end{aligned}
$$

$$
\begin{aligned}
y_{i j k l}=\left(\left(\omega_{0}\right.\right. & \left.+o_{0, i}+o_{0, i j}+o_{0, i j k}\right)+\omega_{3} H T_{r e l, i j k} \\
& \left.+\left(\omega_{1}+\omega_{4} H T_{r e l, i j k}\right) C A_{i j k l}\right) e^{\left(-\left(\omega_{2}+\omega_{5} H T_{r e l, i j k}\right) C A_{i j k l}\right)} \\
& +\varepsilon_{i j k l}
\end{aligned}
$$

$$
\begin{aligned}
y_{i j k l}=\left(\left(\omega_{0}\right.\right. & \left.+o_{0, i}+o_{0, i j}+o_{0, i j k}\right)+\omega_{3} \log H T_{r e l, i j k} \\
& \left.+\left(\omega_{1}+\omega_{4} \log H T_{r e l, i j k}\right) C A_{i j k l)}\right) e^{\left(-\left(\omega_{2}+\omega_{5} \log H T_{r l l i j k}\right) C A_{j i k l}\right)} \\
& +\varepsilon_{i j k l}
\end{aligned}
$$

In order to visualise the intra-stem pattern in SGA, the models were then applied to a single 29-year-old tree $(\mathrm{DBH}=32.8 \mathrm{~cm}$, height $=36.9 \mathrm{~m})$ that had spatial information on ring number from the pith generated at $5 \mathrm{~mm}$ resolution in the radial direction and $100 \mathrm{~mm}$ resolution in the longitudinal direction. This information was generated using the Forecaster growth and yield modelling system (West et al. 2013).

\section{Results}

Most values of spiral grain angle were between $-5^{\circ}$ and $+10^{\circ}$, with a few more extreme values (up to $20^{\circ}$ ) observed (Fig. 2). A linear, or slightly curvilinear, trend in SGA was observed at all heights in the stem, with values of $5-6^{\circ}$ observed in the first few growth rings from the pith decreasing to zero or becoming slightly negative

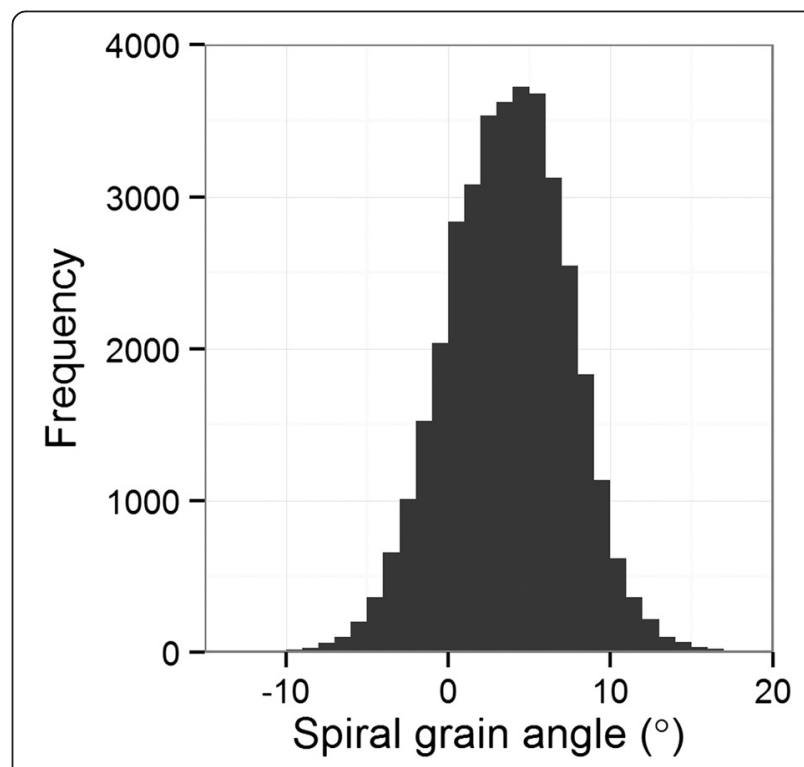

Fig. 2 Histogram showing the distribution of spiral grain angles for all trees in the radiata pine dataset 


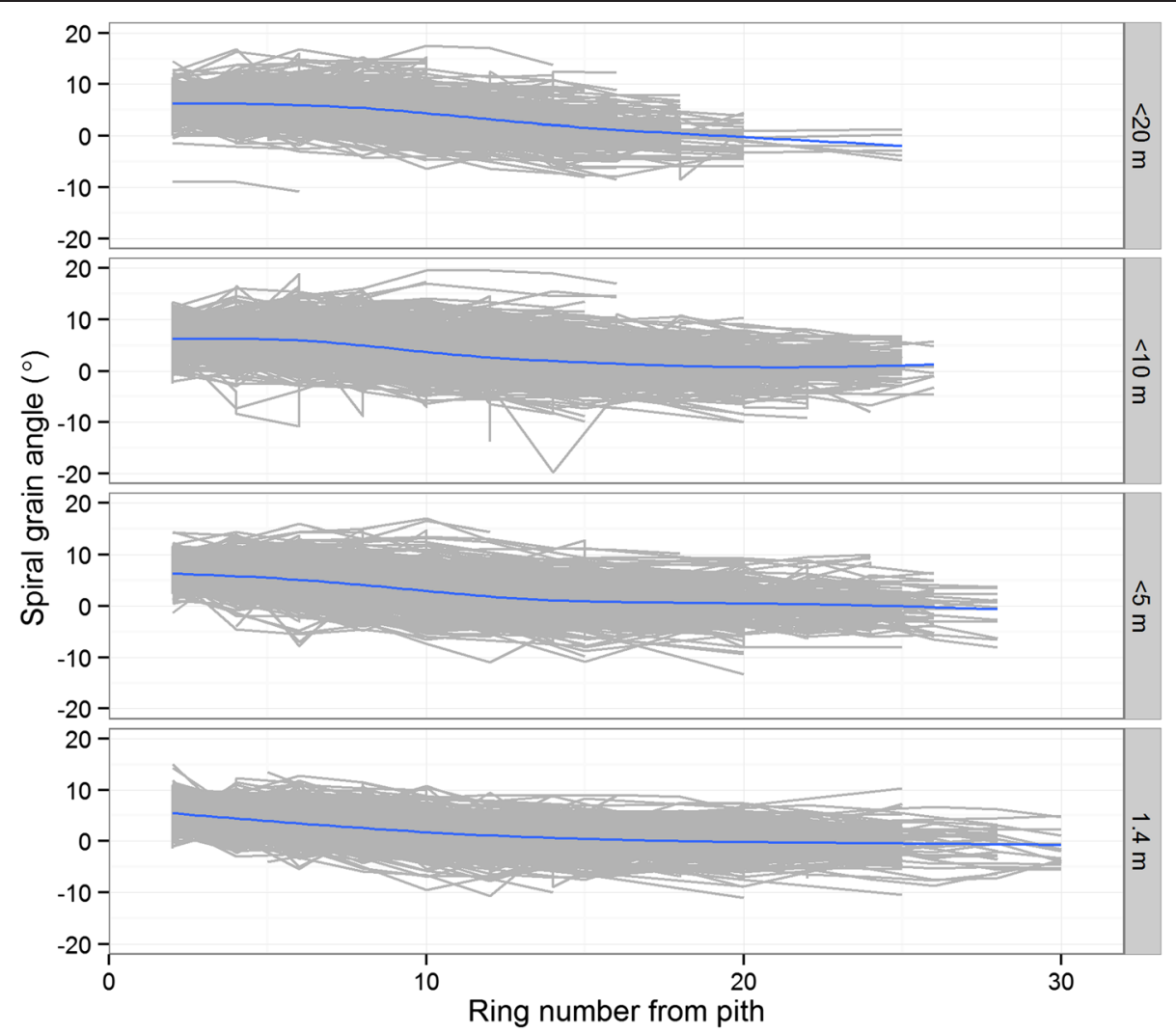

Fig. 3 Radial profiles in SGA for discs taken at different heights within the stem. Each grey line represents the actual observations from an individual tree and the black line is a locally-weighted smoothing function (lowess) fitted to all observations

with increasing ring number from the pith (Fig. 3). Most of the variation in SGA was due to radial variation within the stem (55\%), with a further $23 \%$ due to vertical variation within the stem. Approximately $14 \%$ of the variation in SGA was attributed to differences between trees within a stand, with only $7 \%$ attributed to differences between sites.

\section{Modelling radial variation}

The simple linear model (Eq. (1)) appeared to perform the best of the three models evaluated, having the lowest AIC, and was able to predict approximately $26 \%$ of the variation in SGA based solely on the fixed effect of cambial age $(61 \%$ including the random effects of site, tree and disc) (Table 2). The simple linear model indicates that, on

Table 2 AIC, log-likelihood and fit indices for the models to predict SGA given by Eqs. 1, 2 and 3

\begin{tabular}{lllllll}
\hline Model & AIC & Log-likelihood & \multicolumn{5}{l}{ Fit indices $\left(R^{2}\right)$} \\
\cline { 4 - 7 } & & & Fixed & Site & Tree & Disc \\
\hline Eq. (1) & 147338 & -73661 & 0.26 & 0.31 & 0.51 & 0.61 \\
Eq. (2) & 149165 & -74575 & 0.22 & 0.28 & 0.48 & 0.61 \\
Eq. (3) & 148444 & -74213 & 0.24 & 0.28 & 0.43 & 0.43 \\
\hline
\end{tabular}

average, the value of SGA is approximately $6.1^{\circ}$ at ring two from the pith and on average decreases by $0.3^{\circ}$ with each additional growth ring out from the pith (Table 3 ).

\section{Modelling variation with height}

Adding relative height terms to the linear model (Eqs. (4 and 5)) increased the proportion of variation

Table 3 Parameter estimates and associated standard errors (s.e.) and tests of significance for the models given by Eqs. 1, 2 and 3

\begin{tabular}{lllll}
\hline Parameter & Estimate & s.e. & $t$-value & $p$-value \\
\hline Eq. (1) & & & & \\
$\gamma_{0}$ & 6.708 & 0.156 & 42.883 & $<0.001$ \\
$\gamma_{1}$ & -0.310 & 0.003 & -121.942 & $<0.001$ \\
Eq. (2) & & & & \\
$\delta_{0}$ & 8.506 & 0.161 & 52.775 & $<0.001$ \\
$\delta_{1}$ & -2.316 & 0.020 & -117.628 & $<0.001$ \\
Eq. $(3)$ & & & & \\
$\omega_{0}$ & 7.299 & 0.095 & 77.009 & $<0.001$ \\
$\omega_{1}$ & -2.357 & 0.153 & -154.468 & $<0.001$ \\
$\omega_{2}$ & -0.059 & 0.001 & -62.263 & $<0.001$ \\
\hline
\end{tabular}


in SGA that was explained by these models to approximately $30 \%$ (Table 4 ). This was greater than the amount of variation explained by the addition of height terms to the nonlinear models given by Eqs. (8 and 9), but slightly less than the amount of variation explained by the log-linear models given by Eqs. (6 and 7). However, based on the AIC criterion, the "best" model for explaining the intra-stem variation in SGA is given by Eq. (5). The model given by Eq. (4) had a very similar AIC and also produced similar predictions of SGA, while the models given by Eqs. (6 and 7) only produced positive estimates of SGA, and those given by Eqs. ( 8 and 9) produced some very large negative estimates of spiral grain (up to $-10^{\circ}$ ). Therefore, the linear models given by Eqs. (4 and 5) were preferred over the more complex nonlinear models, even though they do not account for the observed variation within the first few rings from the pith. The parameter estimates for these models are given in Table 5 .

\section{Visualisation of model predictions}

The intra-stem variation in SGA predicted by the model described by Eq. (5) is shown in Fig. 4. This shows that the inner part of the tree has values of SGA of approximately $7-8^{\circ}$ with SGA increasing with height up the stem for a given cambial age. SGA decreases with increasing cambial age with the lowest values found near the base of the tree. The predicted pattern of intra-stem variation in SGA was very similar regardless of whether the longitudinal variation along the stem is modelled as a function of $\mathrm{HT}_{\text {rel }}$ or $\log \left(\mathrm{HT}_{\text {rel }}\right)$ (results not shown).

\section{Discussion}

Spiral grain is apparently more variable and more difficult to model than other important radiata pine wood properties such as density (Kimberley et al. in review) or microfibril angle (Moore et al. 2014). However, the amount of variation in radiata pine SGA that was explained by the models developed here was slightly higher than by the models developed by Gjerdrum et al. (2002)

Table 4 AIC, log-likelihood and fit indices for the models to predict SGA given by Eqs. 4, 5, 6, 7, 8 and 9

\begin{tabular}{lllllll}
\hline Model & AIC & Log-likelihood & \multicolumn{5}{l}{ Fit indices $\left(R^{2}\right)$} \\
\cline { 5 - 7 } & & & Fixed & Site & Tree & Disc \\
\hline Eq. (4) & 49898 & -24939 & 0.29 & 0.35 & 0.56 & 0.58 \\
Eq. (5) & 49829 & -24904 & 0.30 & 0.36 & 0.57 & 0.59 \\
Eq. (6) & 50003 & -24991 & 0.29 & 0.35 & 0.56 & 0.59 \\
Eq. (7) & 50012 & -24996 & 0.29 & 0.36 & 0.57 & 0.59 \\
Eq. (8) & 51143 & -25561 & 0.27 & 0.34 & 0.50 & 0.50 \\
Eq. (9) & 51087 & -25532 & 0.29 & 0.36 & 0.36 & 0.36 \\
\hline
\end{tabular}

Table 5 Parameter estimates and associated standard errors (s.e.) and tests of significance for the models given by Eqs. 4 and 5

\begin{tabular}{lllll}
\hline Parameter & Estimate & s.e. & $t$-value & $p$-value \\
\hline Eq. (4) & & & & \\
$\gamma_{0}$ & 5.831 & 0.278 & 20.955 & $<0.001$ \\
$\gamma_{1}$ & -0.367 & 0.006 & -57.453 & $<0.001$ \\
$\gamma_{2}$ & 1.556 & 0.218 & 7.126 & $<0.001$ \\
$\gamma_{3}$ & 0.341 & 0.027 & 12.779 & $<0.001$ \\
Eq. (5) & & & & \\
$\gamma_{0}$ & 7.319 & 0.282 & 25.920 & $<0.001$ \\
$\gamma_{1}$ & -0.199 & 0.013 & -15.505 & $<0.001$ \\
$\gamma_{2}$ & 0.835 & 0.070 & 11.914 & $<0.001$ \\
$\gamma_{3}$ & 0.073 & 0.008 & 9.483 & $<0.001$ \\
\hline
\end{tabular}

and Fonweban et al. (2013) for Norway spruce and Sitka spruce SGA, respectively.

The patterns of SGA predicted by the models generally confirms what has been described for radiata pine in the literature (e.g. Cown et al. 1991b; Harris 1989; Lausberg et al. 1995; Tian et al. 1995; Watt et al. 2013). In the radial direction, the models developed here showed that there is a predominantly linear decline in SGA with increasing ring number from the pith and the rate of decline decreases with increasing height up the stem. By setting SGA equal to zero in Eq. (4), the age at which SGA transitions from positive (i.e. left handed) to negative (i.e. right handed) was estimated to be 16 years at the base of the tree (i.e. at a relative height of zero). However, previous studies (e.g. Cown et al. 1991b; Watt et al. 2013) have reported near zero values of SGA near the pith followed by an increase to a maximum at ring 6-10 followed by a decline with increasing growth ring from the pith. This pattern was not predicted by the models, but this may be an artefact of the resolution of the data used to develop the models. Many of the trees in the dataset only had SGA measured on every fifth growth ring starting at ring five from the pith, while others had SGA measured on every second ring starting at ring two from the pith. The increase in SGA from the pith to ring 6-10 would not be apparent in the coarser resolution data. Therefore, caution should be exercised when making predictions of SGA in the innermost two to five growth rings using a linear model. Recent advances in measurement techniques (e.g. Riddell et al. 2012) now mean that it is possible to collect higher resolution data on the variation in SGA within a stem, particularly in the circumferential direction, which will enable a better understanding of the patterns of variation as well as providing better data for modelling this variation. 


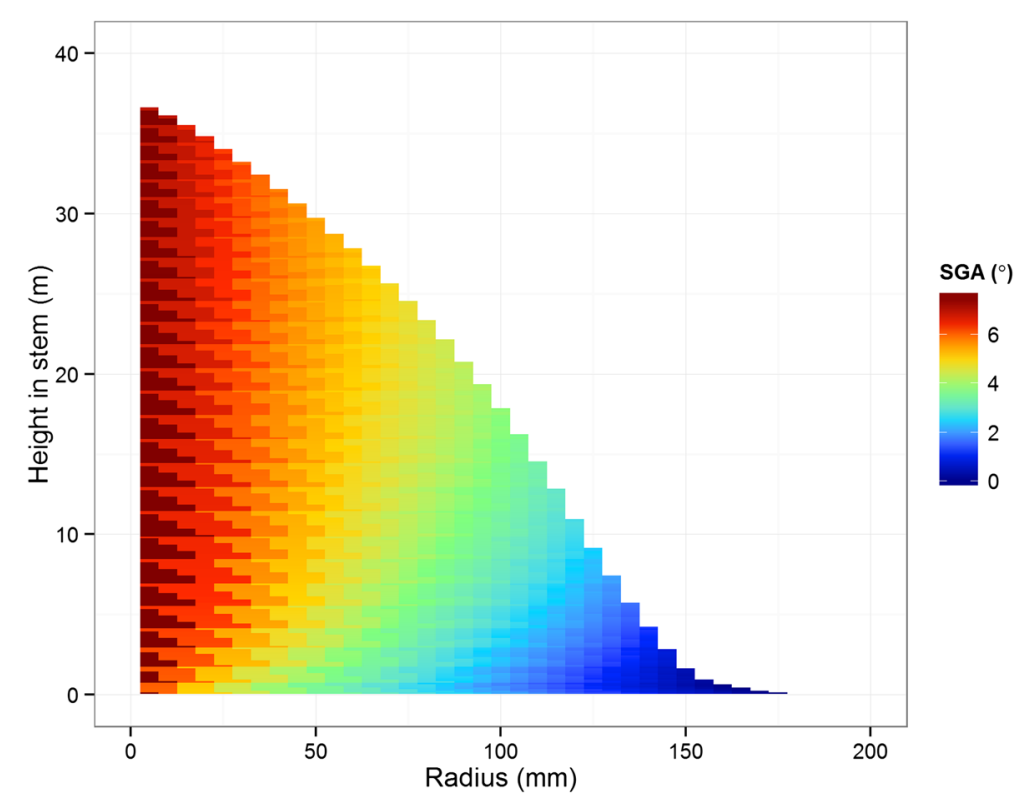

Fig. 4 Intra-stem pattern in SGA predicted by a modified logistic function with a logarithmic relative height term. Parameter estimates for this model (Eq. 5) are given in Table 5 in the text

Previous studies in radiata pine have noted that there is a large amount of tree-to-tree variation in the radial patterns of SGA (Cown et al. 1991b; Watt et al. 2013). The magnitude of this tree-to-tree variation is apparent in this study because when the random effects of site and tree were considered, the total amount of variation in SGA explained by the models almost doubled. The models developed in this study did not include ring width as an explanatory variable as ring width was not measured in most studies. Including a ring width term in future models may improve the amount radial variation in SGA that can be explained as several studies in other species have reported weak positive correlations between ring width and spiral grain angle (Fonweban et al. 2013; Pape 1999).

The models developed here showed that there was a linear increase in SGA with increasing height up the stem, which is consistent with has been reported in previous studies. In the longitudinal direction a general trend of increasing SGA has been noted in the previous studies (Cown et al., 1991b). More quantitative information was provided in a recent study by Watt et al. (2013) who found that SGA in 7-year-old radiata pine tree increased with height up the stem reaching a maximum at a height of $5 \mathrm{~m}$. The additional amount of variation explained by the models when relative height terms were included is based on predicted values of relative height rather than measured values. These values have an error associated with them and it is recommended that tree height is measured in future studies investigating SGA, or other wood properties for that matter.
While site-level variation was relatively small for SGA (i.e. approximately $7.3 \%$ of the total variation), it is still considered worthwhile to investigate this further as previous studies have shown that SGA may be affected by exposure to wind (Eklund and Säll 2000; Fonweban et al. 2013). Other site factors, such as soil type, temperature and rainfall distribution may also contribute and these vary widely across New Zealand, are strong determinants of stand productivity (Watt et al. 2010) and have also been shown to affect other wood properties, most notably density (Palmer et al. 2013). While there are known genetic differences in radiata pine SGA (Burdon and Low 1992; Gapare et al. 2007; Wu et al. 2008), the genetic origin of the trees in the dataset used to develop these models is very diverse it is unlikely for such differences to be observed over and above the other sources of variation in the dataset.

The results from this analysis highlight the issue of corewood in radiata pine which is the wood contained in the first ten or so growth rings from the pith (Cown 1992). In the corewood zone spiral grain angles are consistently high, often exceeding the nominal desired maximum of five degrees (Cown et al. 1991b). Previous utilisation studies in radiata pine have shown that the incidence of twist in sawn timber cut from the corewood zone is much higher than in timber cut from the outerwood zone (Haslett et al. 1991; Ormarsson and Cown 2005) due to the high SGA values, ring curvature, and high longitudinal shrinkage. This presents a challenge since silviculture in New Zealand has traditionally favoured rapid diameter growth, so at harvest age (i.e. 
around 30 years) a substantial volume of each tree is comprised of corewood (30 - $80 \%$ depending on regime and log height class (Cown 1992)). Over the range of stand densities at which radiata pine is typically grown, it is very difficult to restrict the size of the corewood zone.

Further work is required to better understand the patterns of variation in SGA within and between trees, and the drivers of this variation. The data used to develop the models here have low spatial resolution and, therefore, do not capture the full extent of variation that is known to exist within a stem (Cown et al. 2010). If the tree-to-tree variation that is currently included in the models as random variation could be at least partially explained by attributes that could be readily measured on trees or logs, then the predictive power of models could be greatly improved. Future work is planned to refine these models using better techniques to acquire data on SGA (Riddell et al. 2012) and purposely designed experiments that will enable the effects of environmental factors and radial growth rates on SGA to be better understood.

\section{Conclusions}

Based on the analysis of a large dataset of SGA measurements in radiata pine we found that approximately $78 \%$ of the total variation in SGA was due to differences within the stem of a tree, with approximately $7 \%$ due to differences among sites. This intra-stem variation could be modelled as a function of cambial age and relative height within the stem, with the "best" models explaining about $30 \%$ of the variation in SGA. The modelled trends in SGA conformed to those reported by previous studies in radiata pine. High positive values of SGA were found in the first few rings from the pith and SGA declined with increasing ring number from the pith. Spiral grain angle was also found to increase with increasing height up the stem. Because of the silvicultural regimes that radiata pine is grown under (i.e. relatively wide initial spacing and short rotation lengths) the volume occupied by this high SGA wood is relatively high. The models developed in this study are able to be coupled to growth models enabling the impacts of site productivity and silvicultural regimes on the SGA distribution with a tree to be investigated.

\section{Additional file}

Additional file 1: Information about the datasets used to develop the spiral grain angle models. (DOCX $39 \mathrm{~kb}$ )

\section{Competing interests}

The authors declare that they have no competing interests.

\section{Authors' contributions}

JRM conceived the idea for the overall analysis and undertook the data analysis and writing of the manuscript. DJC and RBMcK planned most of the wood quality assessment and contributed to the interpretation of the results and writing of the manuscript. All authors read and approved the final version of the manuscript.

\section{Acknowledgments}

The authors wish to acknowledge Wood Quality Initiative Ltd. who funded several of the studies where SGA data were collected and for allowing publication of the results. Funding for publication of the results was also provided by Future Forests Research Ltd. Dr Charles Sabatia provided assistance with the statistical analysis of the data. Three anonymous reviewers provided helpful comments on an earlier version of this manuscript.

Received: 4 May 2015 Accepted: 21 August 2015

Published online: 03 September 2015

\section{References}

Akaike, H. (1974). A new look at the statistical model identification. IEEE Transactions on Automatic Control, 19, 716-723.

Auty, D, Gardiner, BA, Achim, A, Moore, JR, \& Cameron, AD. (2013). Models for predicting microfibril angle variation in Scots pine. Annals of Forest Science, 70, 209-218. doi:10.1007/s13595-012-0248-6.

Bannan, MM. (1966). Spiral grain and anticlinal division in the cambium of conifers. Canadian Journal of Botany, 44, 1515-1538.

Brazier, JD. (1965). An assessment of the incidence and significance of spiral grain in young conifer stems. Forest Products Journal, 15, 308-315.

Burdon, RD, \& Low, CB. (1992). Genetic survey of Pinus radiata. 6. Wood properties: variation, heritabilities, and interrelationships with other traits. New Zealand Journal of Forestry Science, 22, 228-245.

Cown, DJ. (1992). Corewood (juvenile wood) in Pinus radiata - should we be concerned? New Zealand Journal of Forestry Science, 22(1), 87-95.

Cown, DJ, \& McConchie, DL. (1981). Effects of thinning and fertiliser application on wood properties of Pinus radiata. New Zealand Journal of Forestry Science, 11, 79-91.

Cown, DJ, McConchie, DL, McConchie, MS, Young, GD (1991). Radiata pine wood properies survey. (FRI Bulletin No. 50 (Revised Edition)) Rotorua New Zealand Forest Research Institute.

Cown, DJ, Young, GD, \& Kimberley, MO. (1991b). Spiral grain patterns in plantation-grown Pinus radiata. New Zealand Journal of Forestry Science, $21(2 / 3), 206-216$.

Cown, DJ, Harrington, J, Bourreau, D, Haug, J, \& Lee, J. (2010). Spatial variation in spiral grain: a single stem of Pinus radiata D.Don. New Zealand Journal of Forestry Science, 40, 211-224

Denzler, JK, Weidenhiller, A, \& Golser, M. (2015). Property relationships between spruce logs and structural timber. Scandinavian Journal of Forest Research, 30(7), 617-623. doi:10.1080/02827581.2015.1046479.

R Development Core Team (2013). R: a language and environment for statistical computing. In R Foundation for Statistical Computing (Ed.). Vienna.

Eklund, L, \& Säll, H. (2000). The influence of wind on spiral grain formation in conifer trees. Trees, 14(6), 324-328. doi:10.1007/s004680050225.

Fonweban, J, Mavrou, I, Gardiner, B, \& Macdonald, E. (2013). Modelling the effect of spacing and site exposure on spiral grain angle on Sitka spruce (Picea sitchensis (Bong.) Carr.) in Northern Britain. Forestry, 86(3), 331-342. doi:10.1093/forestry/cpt002.

Gapare, W, Hathorn, A, Kain, D, Matheson, C, \& Wu, H. (2007). Inheritance of spiral grain in the juvenile core of Pinus radiata. Canadian Journal of Forest Research, 37(1), 116-127.

Gjerdrum, P, \& Bernabei, M. (2009). Three-dimensional spiral grain pattern in five large Norway spruce stems. Silva Fennica, 43(3), 457-464.

Gjerdrum, P, Säll, H, \& Storø, HM. (2002). Spiral grain in Norway spruce: constant change rate in grain angle in Scandinavian sawlogs. Forestry, 75(2), 163-170.

Harris, JM. (1989). Spiral grain and wave phenomena in wood formation. Berlin: Springer. Haslett, AN, Simpson, IG, \& Kimberley, MO. (1991). Utilisation of 25-year-old Pinus radiata Part 2: warp of structural timber on drying. New Zealand Journal of Forestry Science, 21(2/3), 228-234.

Jordan, L, Daniels, RF, Clark, A, \& He, R. (2005). Multilevel nonlinear mixed-effects models for the modeling of earlywood and latewood microfibril angle. Forest Science, 51(4), 357-371.

Katz, A, Dunningham, A, \& Gordon, A. (1984). A compatible volume and taper equation for New Zealand Pinus radiata D. Don grown under the direct sawlog 
regime. (FRI Bulletin 67). Rotorua: New Zealand Forest Service, Forest Research Institute.

Kimberley, MO, Cown, DJ, McKinley, RB, Moore, JR (in review). Modelling variation in wood density within and between trees in stands of New Zealand-grown radiata pine. New Zealand Journal of Forestry Science.

Kozlowski, TT, Hughes, FJ, \& Leyton, L. (1967). Movement of injected dyes in gymnosperm stems in relation to tracheid alingnment. Forestry, 40(2), 207-219. doi:10.1093/forestry/40.2.207.

Kubler, H. (1991). Function of spiral grain in trees. Trees, 5, 125-135.

Larson, PR. (1994). The vascular cambium - development and structure (p. 725). New York: Springer-Verlag, Berlin. ISBN 3-540-57165-5.

Lausberg, MJF, Cown, DJ, Gilchrist, K, Skipwith, J, \& Treloar, CR. (1995). Physiological ageing and site effects on the wood properties of radiata pine. New Zealand Journal of Forestry Science, 25(2), 189-199.

Moore, JR, Cown, DJ, \& McKinley, RB. (2014). Modelling microfibril angle variation in New Zealand-grown radiata pine. New Zealand Journal of Forestry Science, 44(1), 25. doi:10.1186/s40490-014-0025-4.

Northcott, PL. (1957). Is spiral grain the normal growth pattern? Forestry Chronicle, 33, 335-352

Ormarsson, S, \& Cown, D. (2005). Moisture-related distortion of timber boards of radiata pine: comparison with Norway spruce. Wood and Fiber Science, 37(3) 424-436.

Palmer, DJ, Kimberley, MO, Cown, DJ, \& McKinley, RB. (2013). Assessing prediction accuracy in a regression kriging surface of Pinus radiata outerwood density across New Zealand. Forest Ecology and Management, 308, 9-16.

Pape, R. (1999). Influence of thinning on spiral grain in Norway spruce grown on highly productive sites in southern Sweden. Silva Fennica, 33(1), 3-12.

Parresol, BR. (1999). Assessing tree and stand biomass: a review with examples and critical comparisons. Forest Science, 45, 573-593.

Pinheiro, JC, \& Bates, DM. (2000). Mixed-effects models in S and S-PLUS. New York: Springer.

Pinheiro, J, Bates, D, DebRoy, S, Sarkar, D, R Core Team (2012). nlme: linear and nonlinear mixed effects models. R package v.3.1-105.

Riddell, M, Cown, D, Harrington, J, Lee, J, \& Moore, J. (2012). Assessing spiral grain angle by light transmission- Proof of concept. IAWA Journal, 33(1), 1-14.

Säll, H (2002). Spiral grain in Norway spruce. Acta Wexionensia No. 22/2002. Sweden: Växjö University Press.

Schulgasser, K, \& Witztum, A. (2007). The mechanism of spiral grain formation in trees. Wood Science and Technology, 41(2), 133-156.

Skatter, S, \& Kučera, B. (1997). Spiral grain - an adaptation of trees to withstand stem breakage caused by wind-induced torsion. Holz als Roh - und Werkstoff, 55(4), 207-213.

Tian, X, Cown, DJ, \& Lausberg, MJF. (1995). Modelling of radiata pine wood properties. Part 1: spiral grain. New Zealand Journal of Forestry Science, 25(2), 200-213.

Tsehaye, A, \& Walker, JCF. (1995). Spiral grain in Canterbury Pinus radiata: within- and between-tree variations and effect on mechanical properties. New Zealand Journal of Forestry Science, 25, 358-366.

Watt, MS, Palmer, DJ, Kimberley, MO, Hock, K, Payn, TW, \& Lowe, DJ. (2010). Development of models to predict Pinus radiata productivity throughout New Zealand. Canadian Journal of Forest Research, 40(3), 488-499.

Watt, MS, Kimberley, MO, Harrington, JJ, Riddell, MJC, Cown, DJ, \& Moore, JR. (2013). Differences in intra-tree variation in spiral grain angle for radiata pine. New Zealand Journal of Forestry Science, 43(1), 12. doi:10.1186/1179-5395-43-12.

West, GG, Moore, JR, Shula, RG, Harrington, JJ, Snook, J, Gordon, JA, \& Riordan MP. (2013). Forest management DSS development in New Zealand. In J Tucek, R Smrecek, A Majlingova, \& J Garcia-Gonzalo (Eds.), Implementation of DSS tools into the forestry practice (pp. 153-163). Slovakia: Technical University of Zvolen.

Wu, HX, Ivković, M, Gapare, WJ, Matheson, AC, Baltunis, BS, Powell, MB, \& McRae, TA. (2008). Breeding for wood quality and profit in Pinus radiata: a review of genetic parameter estimates and implications for breeding and deployment. New Zealand Journal of Forestry Science, 38(1), 56-87.

Young, GD, McConchie, DL, \& McKinley, RB. (1991). Utilisation of 25-year-old Pinus radiata. Part 1: wood properties. New Zealand Journal of Forestry Science, 21(2/3), 217-227

\section{Submit your manuscript to a SpringerOpen ${ }^{\circ}$ journal and benefit from:}

- Convenient online submission

- Rigorous peer review

- Immediate publication on acceptance

- Open access: articles freely available online

- High visibility within the field

- Retaining the copyright to your article

Submit your next manuscript at $>$ springeropen.com 